\title{
The Impact of Life Sciences Developments on the UK Urban Environment
}

\author{
Peter Jones ${ }^{1}$, Martin Wynn ${ }^{2}$, David Hillier ${ }^{3}$ and Daphne Comfort ${ }^{1}$ \\ 1. The Business School, University of Gloucestershire, the Park, Cheltenham GL50 2RH, UK \\ 2. School of Computing and Technology, University of Gloucestershire, the Park, Cheltenham GL50 2RH, UK \\ 3. Centre for Police Sciences, University of South Wales, Pontypridd, Wales CF37 2DL, UK
}

\begin{abstract}
Life sciences urban developments are a relatively recent phenomenon, and follow the emergence of knowledge based urban developments as a potential driver of urban regeneration and local economic growth. The role of these new centres in transforming the inner cities of some of the UK's larger conurbations is examined and the key planning issues are discussed. The article concludes that the key principles of urban planning and control must still apply in shaping the role these new developments have in the UK's evolving urban landscape.
\end{abstract}

Key words: Life sciences developments, biotechnology centres, urban planning, knowledge city, urban management.

\section{Introduction}

Within a number of British cities, there is growing interest in the role that life sciences developments, embracing biotechnology, biomedical and medical technology and health care, can play in the creation and growth of new businesses, employment, and urban regeneration. One of the key recommendations in a recent independent report-designed to review the opportunities for growth in Liverpool-is that 'immediate priority should go to developing the proposed Bio-Innovation Centre to provide growth-stage space, a proof of concept lab, business support centre and incubator' [1]. In a similar vein, the Edinburgh Local Development Plan emphasised that the Scottish Government has identified the Edinburgh BioQuarter as one of two 'enterprise locations in Edinburgh in recognition of their importance to the national economy' [2]. This article examines three recent initiatives to establish life science centres in the cities of Edinburgh, Manchester and Liverpool in the UK, and assesses the planning

Corresponding author: Martin Wynn, B.A., M.A., Ph.D., research fields: information technology and urban planning. and urban development issues that these centres have thrown up. In conclusion, the article discusses what lessons can be learnt that may be of value in the establishment of further life sciences centres in the UK's town and cities.

\section{Life Sciences Urban Developments: Three Case Examples}

The life sciences are generally seen to embrace branches of science such as biology, genetics, biochemistry, ecology and medicine that are concerned with the structure and behaviour of living organisms and their relationships with their environments. More specifically the life sciences sector includes businesses and research and development activities operating in medical technology, medical biochemistry, industrial biotechnology and healthcare. This is clearly a diverse and rapidly developing sector of the economy, and it has different elements, which are, in turn, reflected in the names used to describe developments and development proposals in different urban contexts in the UK. However a few simple illustrative examples provide a picture of some of the characteristics of these developments. 


\subsection{The Edinburgh BioQuarter}

The Edinburgh BioQuarter officially opened in 2012 and is located on a 100 acre site adjacent to the Edinburgh Royal Infirmary some three miles south of the city centre. It describes itself as being at the heart of Scottish Life Sciences' and is essentially an academic medical centre that looks to combine biomedical research from the University of Edinburgh with the clinical expertise of NHS Lothian and a team of industry professionals. The BioQuarter is a joint venture between Scottish Enterprise, NHS Lothian, The University of Edinburgh and Alexandria Real Estate Equities Inc. The strategic vision is that the concentration of clinical and academic expertise of the Royal Infirmary, the Queens Medical Research Institute and the Edinburgh Medical School will provide 'companies locating at BioQuarter with wide ranging access to outstanding facilities, researchers, business support and recruitment opportunities in an environment designed to foster innovation and collaboration.'

The BioQuarter building itself is a three-story multiple occupancy building for life science companies from start-ups to major international businesses, and facilities Include a range of laboratory units, offering between 250 and 700 square feet of space. This space comprises secure freezer rooms, individual serviced office suites, meeting rooms, an audio visual presentation suite, space constructed to 'shell and core' finish, ready for bespoke fit out to meet individual company requirements, a manned reception desk and access to catering provision. The building's amenities also include barrier secured car parking, CCTV monitoring of external and internal public areas, card controlled security access, dedicated facilities for the delivery and storage of chemicals, gases and waste, a dedicated power supply with full generator support, fibre optic connectivity, Wi-Fi in public spaces and a secure IT hub. Scottish Enterprise offer a range of tailored business support services to occupiers as the BioQuarter is located within a Tier 3 area in which small to medium sized companies are eligible for up to $20 \%$ financial support in Regional Selective Assistance. Companies who have recently moved into the BioQuarter include R Biomedical, who specialise in research, development and commercialisation of regenerative medicine, and Science Squared, an innovative online communications company, and Marks and Clarks, a firm of attorneys who specialise in patents, trademarks and intellectual property rights.

\subsection{The Manchester MediPark}

The proposed Manchester MediPark, adjacent to Wythenshawe and the University Hospital in South Manchester, is one of the key components of the Greater Manchester Enterprise Zone. Manchester City Council sees it as 'a significant opportunity to create growth by developing a focus for world class biosciences, healthcare and related manufacturing and production' [3]. The proposed Medipark will look to build 'upon the well-established concentration of health research, learning and clinical expertise' to facilitate the translation of research into commercial manufacturing. It will provide accommodation for both established businesses, which are looking to use the location as a vehicle for growth and for new businesses planning to capitalise on the research and development capabilities available within this area of the city.

Manchester City Council suggests that a demand analysis has led to the identification of three types of potential occupiers, namely health care related companies; research and development companies; and companies providing supporting facilities. Firstly, there is seen to be a demand for larger floor spaces from commercially driven healthcare and life sciences companies, who will benefit from an association with the MediPark brand. The demand here will be for office space, light industrial, manufacturing and high tech workspaces. This type of space will allow growing companies opportunities to expand and will allow large companies to operate their office and manufacturing 
functions in MediPark, alongside their research and clinical trading operations. The research and development companies may be specialist life sciences and healthcare companies who will require both wet and dry laboratories and fast track clinical trial facilities. The third group will offer supporting facilities, including restaurants, crèches, banks, a gym, convenience retail outlets, dry cleaners and a pharmacy, and as such will provide 'a rounded real estate offer.'

\subsection{The Liverpool BioInnovation Centre}

The proposed Liverpool BioInnovation Centre, alongside the new Royal Liverpool hospital in the heart of the city, is to be a five storey building offering some 80,000 square feet of floor space. The Centre has been designed to have two components. On the one hand, it will provide incubation and 'grow-on' space while, on the other hand, it will be a development centre to provide assistance to support both resident companies and other companies with premises elsewhere to become 'investor ready' and to assist in the commercialisation of their intellectual property plans. More specifically the development centre is seen to be vitally important in establishing an integrated business creation environment to support the development of new ideas, innovation and both new and growing companies.

The Centre will provide specialist accommodation to allow small and medium sized companies to become established and grow. Here the focus will be on the creation of a dedicated environment for the convergence of clinical and academic research and one designed to bridge what can be a difficult gap between the concept and the market. As such the Centre will act as a high profile focus to stimulate and harvest concepts and research that emerge within the city's universities, identify concepts and research findings that seem likely to have commercial potential, and a mechanism to refine and support commercial applications for investment. More specifically the physical accommodation will include a number of small chemistry and biology laboratory suites, laboratory support facilities, bookable meeting rooms and office spaces, a 90 person conference room, flexible and open plan networking areas, and business support and commercialisation centre offices.

\section{Urban Development and Planning Issues}

While local planning authorities adopt their own distinctive approaches to the type of life sciences developments illustrated above, such developments have generally generated a positive response. Thus the National Planning Policy Framework advises that local authorities should 'positively seek opportunities to meet the development needs of their areas' and that to help achieve economic growth, local planning authorities should plan proactively to meet the development needs of business and support an economy fit for the 21st century' [4]. At the local authority level, the proposed development of the MediPark is very much in line with Manchester's Core Strategy in that its proposed site is designated as an Economic Improvement Area. More specifically the Core Strategy articulates that the proposed MediPark site is expected to be developed to provide health facilities and that it presents an opportunity for growth in research and development related to the bio-sciences. More locally, some of the key objectives of the Wythenshawe Strategic Regeneration Strategy have implications for the proposed MediPark in that they emphasize the importance of education and learning and the enhancement of educational opportunities and the development of an integrated transport strategy to improve access to jobs.

While local planning authorities have generally looked to support life science based developments within their jurisdiction, some have provided specific guidance to developers. Edinburgh City Council, for example, have published 'Supplementary Guidance' for the proposed extension of the existing BioQuarter in order 'to realise the full life science potential of the Edinburgh BioQuarter, in a mixed use urban quarter, 
which protects and enhances the landscape setting of the city.' More specifically the Edinburgh City Council reports that it will support proposals for development within The Edinburgh BioQuarter which adhere to a number of development principles [9]. The City Council recognises, for example, that a high density urban form of development will be required to allow the development to meet its full potential and that this will, in turn, foster a sense of place attractive to workers and visitors. That said, the City Council stresses that buildings should achieve the highest level of sustainable design, reduce carbon and greenhouse gas emissions, and make efficient use of energy resources and land. While the City Council suggests that it will support ancillary uses 'to promote place making and provide local services and evening and weekend activity' it stresses that 'the type and quantity of ancillary uses must support, not jeopardize, the overall life science purpose of the Edinburgh BioQuarter.' More generally, the City Council also recommends that 'development at the BioQuarter must respect the site's sensitive location within the wider landscape of the city' and that 'the extent of development and building heights, particularly on the upper slopes, must be carefully managed.'

A wide range of urban/community and economic benefits are currently being claimed for of the type of life sciences based developments illustrated above. Manchester City Council, for example, have argued that the development of the MediPark will deliver significant economic impacts and play an important role in the recovery and growth of the City Region from 2015.' More specifically the City Council predict that the development will eventually accommodate up to some 2,000 jobs over 12 years with a mix of high tech and office based employment opportunities. More generally the City Council further estimate the development will generate $£ 190$ million in Gross Value Added over its lifetime and that this in turn will provide a further boost to the health sector in and around the city. The belief is that the development proposals, essentially based around providing incentives, collaborative arrangements, a high quality environment and access to national and international markets, will attract new private sector investment and that many of the employment opportunities created in MediPark will be additional to the city region and more generally it will 'make a major contribution to achieving a number of the City Regions Strategic Economic objectives.'

A similar range of benefits are claimed for the development of the Liverpool BioInnovation Centre. The benefits to the Liverpool City Region are seen to include the creation of new employment opportunities typically creating higher value and higher skilled jobs than other sectors, a halo effect, which will enhance the Liverpool City region's life sciences business image, increase the business rate revenue, and foster the creation and continued growth of an entrepreneurial culture. More generally the Edinburgh BioQuarter partners suggest that it will bring potential benefits both to the city and to Scotland, that it will be highly significant in terms of the economy and job creation, that it will attract people to work in, stay in, and visit, and that it will complement urban regeneration in the surrounding area.

Manchester City Council argue that the development of the MediPark will provide a number of positive benefits for the surrounding community, and here the accent is to be on community engagement and on maximizing the opportunities for the benefit of local residents. The City Council acknowledges that nearby Wythenshawe is one of the most deprived areas within the UK and suggests that many of the 2,000 jobs available in MediPark will be taken by local people, and that this will in turn provide a major opportunity to provide opportunities for local students and school leavers and more generally to raise aspirations, particularly amongst youngsters, and to reduce unemployment in the area. At the same time, it is argued that the proposed development will provide a boost to the local construction industry and generate a range of supply chain opportunities. The 
proposed development also includes a number of physical improvements, including the establishment of a new community hub, designed to increase the range and the quality of community facilities, greater public transport opportunities, and the creation of more pedestrian links, which will all benefit local people.

\section{Concluding Remarks}

Within a number of cities there is growing interest and enthusiasm, almost a sense of excitement, about the role that life sciences based developments can play in urban regeneration and economic growth. More generally these developments are part of the on-going process of urban change and reinvention. They parallel, and to some extent overlap with, the emergence of knowledge-based urban development (KBUD) as a strategy for embedding knowledge related industries and institutions within the urban fabric as engines of growth and innovation [10]. The three case studies discussed above suggest that the factors outlined below are vitally important in underpinning successful implementation. Some of the issues highlighted here clearly resonate with implementation success factors discussed in a wider planning context in the post war era.

Administrative complexity is a characteristic of the planning process in general which can delay plan approval and undermine momentum. The nature of the different public and private agencies involved at technical, financial and political levels in the preparation and implementation of life sciences developments means that a certain degree of complexity is inevitable. At the same time, high failure rates amongst small new companies and the acquisition of successful companies by larger corporations and their relocation within larger existing premises can also cause problems for new life sciences developments. Public support and commitment are essential, and the harnessing of multiple partners from educational and health sectors as well as private sector developers has generally engendered public support for these developments. The job and revenue creation potential of these developments has also attracted a favourable response, particularly in depressed inner city areas. Planners have learned to their cost that public involvement is not a rubber stamp operation, but rather an essential part of the plan formulation process, concerned with the allocation of resources and development of priorities and objectives. This appears to have been managed well in these developments, to gain public support and project momentum.

Policy options and review processes are therefore integral elements in the initial preparation of proposals, which allow alternative courses of action to be assessed while developing preferred options. Within this process is the iterative cycle of maximizing benefits; the variety of potential occupiers catered for in these developments, allied to the wide range of technology and industry related infrastructure provided, has been a clear positive in attracting new industries and partners. Financial support and organization, and their integration into the plan proposals, create both a sense of realism which will promote implementation and also help gain wider political support. The role of the city councils and other funding agencies in providing part funding has been critical in moving these projects forward, and ensuring financial gain is seen to be balanced with broader social and physical planning gains. Timing, phasing and impact assessment are significant considerations in determining implementation details. The dovetailing of these initiatives with other local and broader national and regional policies and incentives has been a key aspect in successfully guiding and controlling growth and change as a continuous process, and not merely as stages leading to an ideal end state.

The obvious benefits of the projects discussed above suggest that an appropriate balance is being struck between public good and private sector interests. These projects will inevitably involve conflicts and trade-offs which are widely accepted as a 
necessary part of the compromise that is entailed in urban development. It highlights the truth that in planning, perhaps more than any other sphere in the UK, fresh legislation, new administrative arrangements, and innovative inducements are tried and tested with an astounding rapidity that underpins the continuous evolution and continued credibility of the planning system itself.

\section{References}

[1] The RT Hon Lord Heseltine and Sir Terry Leahy 2011. "Rebalancing Britain: Policy or slogan-Liverpool City Region-Building on its Strengths: An independent report." https://www.gov.uk/government/uploads/system/ uploads/attachment_data/file/32080/11-1338-rebalancin g-britain-liverpool-city-region.pdf.

[2] The City of Edinburgh Council 2012. Edinburgh Local Development Plan: Proposed Plan http://217.174.251.127/plans/ldp/LDPProposedPlanMarc h2013.pdf.

[3] Manchester City Council 2012. Report To Economy Scrutiny Committee-12 December 2012. www.manchester.gov.uk/egov_downloads/Medipark.pdf.

[4] Department for Communities and Local Government
2012. National Planning Policy Framework, https:/www.gov.uk/government/uploads/system/uploads/ attachment_data/file/6077/2116950.pdf.

[5] Department for Business Innovation and Skills 2011. Strategy for UK life Sciences, https://www.gov. uk/government/uploads/system/uploads/attachment_data/ file/32457/11-1429-strategy-for-uk-life-sciences.pdf.

[6] Edinburgh BioQuarter 2011a. Edinburgh BioQuarter, http://www.sdi.co.uk/ /media/SDI/Files/documents/life-s ciences/edinburgh-bioquarter-at-the-heart-of-scottish-lifesciences.pdf.

[7] Edinburg BioQuarter 2011b Edinburg BioQuarter, http://www.sdi.co.uk/ /media/SDI/Files/documents/life-s ciences/edinburgh-bioquarter-property-brochure.pdf.

[8] Institute for Small Businesses and Entrepreneurship 2011. International Entrepreneurship: UK Biosciences Incubators-A future Role in Foreign Direct Investment, http://www.isbe.org.uk/LBIC.

[9] The City of Edinburgh City Council 2013. Edinburgh BioQuarter and South East Wedge Parkland: Supplementary Guidance-Draft for Consultation, http://www.edinburgh.gov.uk/downloads/file/10635/bioq uarter_and_sew_parkland_sg.

[10] Yigitcanlar, T. 2011. "Position Paper: Redefining Knowledge Based Urban Development." International Journal of Knowledge-based Development 2 (4): 340-56. 